\title{
A prospective longitudinal study of apathy in Alzheimer's disease
}

\author{
S E Starkstein, R Jorge, R Mizrahi, R G Robinson
}

J Neurol Neurosurg Psychiatry 2006;77:8-11. doi: 10.1136/jnnp.2005.069575

See end of article for authors' affiliations

....................

Correspondence to: Professor S E Starkstein

Education Building T-7, Fremantle Hospital, Fremantle, 6959 WA Australia; ses@cyllene. uwa.edu.au

Received 11 April 2005 Revised 15 June 2005 Accepted for publication 4 July 2005

\begin{abstract}
Background: Apathy and depression are the most frequent behavioural and psychiatric disorders in Alzheimer's disease, and may both have a negative impact on the progression of the illness.

Objectives: To examine the clinical correlates of apathy in Alzheimer's disease (AD), and to determine whether apathy is a significant predictor of more rapid cognitive, functional and emotional decline.

Methods: Using a structured psychiatric evaluation, we examined a consecutive series of 354 subjects meeting clinical criteria for AD. Apathy was assessed by the Apathy Scale, and diagnosed using standardised criteria. Additional measurements included scales for depression, functional impairment, and global cognitive functions. A follow up evaluation was carried out in 247 patients ( $70 \%$ of the total sample) between 1 and 4 years after the baseline evaluation.

Results: Apathy was significantly associated with older age $(p=0.009)$, and a higher frequency of minor and major depression $(p<0.0001)$. Apathy at baseline was a significant predictor of depression at follow up $(p=0.01)$, and was associated with a faster cognitive $(p=0.0007)$ and functional decline $(p=0.006)$. Conclusions: Apathy in $A D$ is a behavioural marker of a more aggressive dementia, characterised by a faster progression of cognitive, functional, and emotional impairment.
\end{abstract}

A pathy is defined as lack of motivation relative to the individual's previous level of functioning, and is manifested by diminished goal directed cognition and behaviour. ${ }^{1}$ Among patients with Alzheimer's disease (AD) the frequency of apathy has been reported to range from $25 \%$ to $50 \% .^{2}$ Depression is the main psychiatric correlate of apathy in $\mathrm{AD}^{3}$ an expected finding given that loss of interest and motivation is a conspicuous symptom of both syndromes. However, apathy should not be construed as a mere symptom of depression, given that about half of $\mathrm{AD}$ patients with apathy have no concomitant depression. ${ }^{3}$ Apathy is most prevalent in severe dementia, ${ }^{2}$ and could result from the serious functional restrictions imposed by the cognitive deficits. Several studies have demonstrated a significant association between apathy and both reduced metabolic activity in prefrontal regions ${ }^{4-6}$ and more severe parkinsonism, ${ }^{3}$ suggesting that neuropathological changes in specific brain areas may underlie the high frequency of apathy in AD.

For the present study, we examined a large consecutive series of patients with $\mathrm{AD}$ using reliable instruments to measure the severity of apathy, to rate the presence and severity of depression, and to determine the stages of $\mathrm{AD}$. We expected apathy at baseline to be significantly associated with more severe dementia and depression, and to predict a faster cognitive and functional decline.

\section{METHODS}

The AD group included a consecutive series of 354 outpatients attending the dementia clinic at a tertiary neurology centre in Buenos Aires, Argentina, between January 1996 and October 2001 for evaluation and treatment of progressive cognitive decline. The inclusion criteria were: (a) NINCDSADRDA criteria for probable $\mathrm{AD}^{7}(b)$ no history of strokes, closed head injuries with loss of consciousness, or other neurological disorder with central nervous system involvement; (c) normal results on laboratory tests (to rule out other aetiologies of dementia); (d) no focal lesions on magnetic resonance imaging; and (e) a Hachinski Ischemic Score (HIS)
$<4$. The institutional human subjects committee approved the study.

\section{Psychiatric examination}

After written informed consent was obtained from patients and their respective caregivers, a psychiatrist blind to neurological findings assessed patients with the following instruments:

- Structured Clinical Interview for DSM-IV (SCID), ${ }^{8}$ a semistructured diagnostic interview for making the major Axis I DSM-IV diagnoses. A psychiatrist administered the SCID with the patient and at least one first degree relative. Based on the SCID responses, DSM-IV Axis I diagnosis of major depressive episode and the DSM-IV research diagnosis of minor depression disorder were made. ${ }^{9} \mathrm{We}$ have previously demonstrated the validity of this diagnostic strategy in patients with $\mathrm{AD} .^{10}$

- Mini-Mental State Examination (MMSE), ${ }^{11}$ an 11 item test found to be valid and reliable in globally assessing a limited range of cognitive functions.

- Clinical dementia rating (CDR), ${ }^{12}$ a global rating device for dementia stages.

- Hamilton depression scale (HAM-D), ${ }^{13}$ a 17 item interviewer rated scale that measures psychological and autonomic symptoms of depression.

- Apathy Scale (AS), ${ }^{14}$ comprising 14 items, which are scored by the patient's relative or caregiver. We have demonstrated the reliability and validity of the AS in AD. Diagnoses of apathy were generated based on caregivers' ratings on the AS using the procedure and diagnostic criteria reported previously. ${ }^{3}$ Briefly, apathy was diagnosed

Abbreviations: $A D$, Alzheimer's disease; $A D L$, activities of daily living; AS, Apathy Scale; CDR, Clinical Dementia Rating; DSM-IV, Diagnostic and statistical manual of mental disorders, 4 th edition; FIM, Functioning Independence Measure; HAM-D, Hamilton depression scale; HIS, Hachinski Ischemic Score; MMSE, Mini Mental State Examination; SCID, Structured Clinical Interview for DSM-IV 
whenever patients had poor or no motivation (item 7), interest (items 1 and 2), or effort (items 4 and 9), and had feelings of indifference or lack of emotions most or all of the time (items 10 and 13).

- Functioning Independence Measure (FIM), ${ }^{16}$ an 18 item ordinal scale assessing self care, sphincter control, mobility, locomotion, communication, and social cognition. Higher scores indicate less impairment in activities of daily living (ADL).

\section{Follow up examination}

A follow up evaluation was carried out on 247 of the 354 patients (70\%) between $\mathrm{l}$ and 4 years after the initial evaluation, using the same instruments assessed at baseline. Some patients could not be followed up; reasons included death during the follow up period $(\mathrm{n}=21 ; 20 \%)$, severe dementia that precluded assessment $(\mathrm{n}=49 ; 46 \%)$, moved to another city or could not be traced $(n=23 ; 21 \%)$, or refused another evaluation $(n=14 ; 13 \%)$. Patients without follow up were significantly older than patients with follow up (mean (SD) age: $73.1(8.1) \vee 70.7(7.4) ; \mathrm{t}=2.9, \mathrm{df}=352, \mathrm{p}=0.003)$, had lower MMSE scores (mean (SD) scores: 15.2 (7.1) $v 22.2$ (5.6); $\mathrm{t}=9.9, \mathrm{df}=352, \mathrm{p}<0.0001)$, and more severe apathy (mean (SD) scores: 22.7 (9.3) $v 18.1(9.6) ; \mathrm{t}=4.4 \mathrm{df}=352$, $\mathrm{p}<0.0001)$. In total, $207(84 \%)$ of the 247 patients with a follow up were assessed 1-2 years after the baseline evaluation, 30 patients $(12 \%)$ had a follow up evaluation $2-3$ years after the baseline evaluation, and 10 patients $(4 \%)$ had a follow up evaluation 3-4 years after the baseline evaluation.

\section{Statistical analysis}

Statistical analysis was carried out using means and SDs, Student's $t$ test, and one way and repeated measures analysis of variance with post hoc planned comparisons (Tukey's test for unequal samples). Frequency distributions were calculated using $\chi^{2}$ and Fisher's exact tests. All $\mathrm{p}$ values are two tailed. To reduce the risk of type I errors, the $\mathrm{p}$ value was set at 0.01 .

\section{RESULTS}

\section{Baseline demographic and clinical findings}

Apathy was diagnosed in 120 of the 354 patients (24\%). Patients with apathy were significantly older, had more severe cognitive deficits, and more severe impairments in ADLs than patients without apathy (table 1). The frequency of apathy was $14 \%(n=8)$ in very mild $\mathrm{AD}$ (CDR 0.5$), 28 \%$ $(\mathrm{n}=39)$ in mild $\mathrm{AD}(\mathrm{CDR} 1), 39 \%(\mathrm{n}=43)$ in moderate $\mathrm{AD}$ (CDR 2), and $61 \%(n=30)$ in severe $A D(C D R 3)$. A hypothesis of unequal frequency of apathy based on the stage of dementia was statistically substantiated $\left(\chi^{2}=29.9\right.$, $\mathrm{df}=3, \mathrm{p}<0.0001)$. Of the 74 patients with major depression, $41(55 \%)$ had apathy, compared with 35 of $85(41 \%)$ patients with minor depression, and 45 of 195 (23\%) patients without depression. A hypothesis of unequal frequency of apathy based on the presence of depression was statistically substantiated $\left(\chi^{2}=26.8, \mathrm{df}=2, \mathrm{p}<0.0001\right)$.

\section{The relationship between apathy and depression}

We first examined whether the onset of depression during the follow up period was associated with increasing apathy. This analysis included patients with neither depression nor apathy at baseline $(\mathrm{n}=97)$, who at follow up had major $(n=6)$, minor $(n=18)$, or no depression $(n=73)$. We calculated a two way analysis of variance with repeated measures, with depression diagnosis at follow up (major, minor, and no depression) as the between group factor, AS scores as the dependent variable, and time (baseline $v$ follow up) as the repeated measure. There was a significant group
$\left(\mathrm{F}_{(2,94)}=5.58, \mathrm{p}=0.005\right)$ and time $\left(\mathrm{F}_{(1,94)}=16.3, \mathrm{p}<0.0001\right)$ effect, but no significant interaction $\left(\mathrm{F}_{(2,94)}=2.11\right.$, NS) (table 2). These results demonstrate an overall significant increment in apathy scores during the follow up period, and overall higher apathy scores for the group with major depression at follow up. The lack of a significant group by time interaction indicates that the increment in apathy scores during the follow up period was of similar magnitude for all three groups.

We next examined whether apathy at baseline might predict more severe depression at follow up. This analysis included patients without depression at baseline $(\mathrm{n}=108)$, who were subdivided into groups having apathy $(n=21)$ or not $(n=76)$ at both evaluations. We calculated a two way analysis of variance with repeated measures, with apathy at baseline and at follow up (present $v$ absent) as the between group factor, HAM-D scores as the dependent variable, and time (baseline $v$ follow up) as the repeated measure. There was a significant group $\left(\mathrm{F}_{(1,95)}=7.50, \mathrm{p}=0.007\right)$ and time $\left(\mathrm{F}_{(1,95)}=10.8, \mathrm{p}=0.001\right)$ effect, and a significant group by time interaction $\left(\mathrm{F}_{(1,95)}=5.52, \mathrm{p}=0.01\right)$ (apathy group (baseline and follow up HAM-D scores; mean (SD): 5.3 (4.3) and 10.0 (11.0), respectively; no apathy group: 4.4 (3.5) and 5.2 (4.7), respectively). The mean (SD) baseline to follow up interval was 18.6 (9.5) months for the apathy group, and 16.7 (10.1) months for patients without apathy. These results demonstrate a significant increase in depressive symptoms during follow up for non-depressed patients with apathy compared with non-depressed patients without apathy.

\section{Apathy and functional decline}

To determine whether apathy predicted a faster cognitive and functional decline we examined longitudinal differences on MMSE and FIM scores for the following groups: (a) apathy at baseline and follow up, $(b)$ no apathy at baseline or at follow up, and $(c)$ no apathy at baseline and apathy at follow up (the small sample of 8 patients with apathy at baseline but no apathy at follow up was not included in this analysis) (table 3). Repeated measures analysis of variance for MMSE scores, with baseline MMSE scores as the covariate, showed a significant group effect $\left(\mathrm{F}_{(2,236)}=8.70, \mathrm{p}=0.0002\right)$, the expected time effect $\left(\mathrm{F}_{(1,236)}=33.8, \mathrm{p}<0.0001\right)$, and $\mathrm{a}$ significant group by time interaction $\left(\mathrm{F}_{(2,236)}=7.39\right.$, $\mathrm{p}=0.0007$ ) (table 3$)$. On individual group comparisons, patients with no apathy at baseline but apathy at follow up had a significantly greater decline on MMSE scores than patients without apathy at both evaluations $\left(\mathrm{F}_{(1,177)}=15.7\right.$, $\mathrm{p}<0.0001)$.

A two way analysis of variance with repeated measures for FIM scores showed a significant group $\left(\mathrm{F}_{(2,216)}=13.8\right.$, $\mathrm{p}<0.0001)$ and time $\left(\mathrm{F}_{(1,216)}=31.0, \mathrm{p}<0.0001\right)$ effect, and a significant group by time interaction $\left(\mathrm{F}_{(2,216)}=5.17\right.$, $\mathrm{p}=0.006$ ) (table 3 ). On individual group comparisons, patients with no apathy at baseline but apathy at follow up had a significantly greater functional decline than patients without apathy at both evaluations $\left(\mathrm{F}_{(1,163)}=11.2, \mathrm{p}<0.001\right)$.

There were no significant between group differences at the follow up evaluation in the frequency of patients on anticholinesterase drugs (no apathy at both evaluations: $36 \%$, no apathy at baseline, apathy at follow up: $47 \%$, apathy at both evaluations: $37 \%)$, neuroleptics $(15 \%, 25 \%$, and $25 \%$, respectively), anxiolytics (23\%, 24\%, and $21 \%$, respectively), and antidepressants (19\%, 26\%, and 30\%, respectively).

\section{DISCUSSION}

We examined the association between apathy and depression in a longitudinal study that included a large series of patients with AD. There were several important findings. Firstly, apathy was significantly associated with older age, and the 
Table 1 Demographic and clinical findings

\begin{tabular}{|c|c|c|c|c|c|}
\hline & Apathy & No apathy & $t$ or $\chi^{2}$ & df & $\mathbf{p}$ \\
\hline \multicolumn{6}{|l|}{ Patient demographics } \\
\hline No. of patients & 120 & 234 & & & \\
\hline Female, n (\%) & $64(77)$ & $62(146)$ & 0.10 & 1 & NS \\
\hline Age (years), mean (SD) & $73.1(7.3)$ & $70.9(7.8)$ & 2.61 & 352 & 0.009 \\
\hline Education (years), mean (SD) & $11.5(8.3)$ & $12.2(6.2)$ & 0.06 & 352 & NS \\
\hline \multicolumn{6}{|l|}{ CDR rating, $\mathrm{n}(\%)$} \\
\hline 0.5 & $14(8)$ & $86(50)$ & & & \\
\hline 1 & 28 (39) & $72(98)$ & & & \\
\hline \multirow[t]{2}{*}{2} & $39(43)$ & $61(67)$ & & & \\
\hline & $61(30)$ & 39 (19) & 29.9 & 3 & $<0.0001$ \\
\hline \multicolumn{6}{|l|}{ Medications, n (\%) } \\
\hline Antidepressants & $13(16)$ & $6(14)$ & 5.53 & 1 & 0.01 \\
\hline Neuroleptics & $14(17)$ & $7(16)$ & 5.04 & 1 & NS \\
\hline Anxiolytics & $16(19)$ & $18(41)$ & 0.16 & 1 & NS \\
\hline \multicolumn{6}{|l|}{ Test score, mean (SD) } \\
\hline MMSE & $16.6(7.0)$ & $20.9(6.5)$ & 5.57 & 352 & $<0.0001$ \\
\hline HAM-D & $13.6(8.6)$ & $8.5(6.0)$ & 5.41 & 352 & $<0.0001$ \\
\hline AS & $29.6(4.9)$ & $14.7(7.5)$ & 19.4 & 352 & $<0.0001$ \\
\hline $\mathrm{FIM}^{*}$ & $59.7(20.2)$ & 67.7 (15.9) & 3.80 & 332 & $<0.0001$ \\
\hline
\end{tabular}

frequency of apathy increased from 14\% in the stage of very mild $\mathrm{AD}$ to $61 \%$ in the stage of severe AD. Secondly, apathy was significantly associated with both major and minor depression. Thirdly, apathy at baseline was a significant predictor of depression at follow up. Fourthly, AD patients who developed apathy during the follow up period had a significantly greater cognitive and functional decline than $\mathrm{AD}$ patients without apathy.

Before further comments, several limitations of our study should be pointed out. Firstly, we obtained longitudinal information on $70 \%$ of our sample. The main reasons for lack of follow up were death or extreme dementia, and change of address. Patients without a follow up evaluation were older and had more severe dementia and apathy than patients with a follow up, thus our findings should be restricted to patients with mild or moderate AD. Secondly, duration of follow up was not homogeneous, ranging from 1 to 4 years. However, $84 \%$ of the patients were assessed 1-2 years after the baseline evaluation, and duration of follow up was similar for all the subgroups that were analysed. Thirdly, apathy in AD may be better suited to dimensional rather than a categorical diagnosis, and this issue should be clarified in future studies. However, we have demonstrated the reliability and validity of a categorical diagnosis of apathy in $\mathrm{AD} .{ }^{3}{ }^{17}$ Finally, patients were recruited from a tertiary neurology centre, which may have biased our sample towards cases with relatively more severe psychopathology.

To our knowledge, this is the largest longitudinal study on the clinical correlates and prognostic implications of apathy in $\mathrm{AD}$. We found that patients with apathy were significantly older than patients without, and the frequency of apathy was highest among patients with severe dementia. Patients with advanced $\mathrm{AD}$ are greatly limited in the range of goal directed

Table 2 AS scores for patients without depression or apathy at baseline and either major, minor, or no depression at follow up

\begin{tabular}{llll}
\hline $\begin{array}{l}\text { Level of } \\
\text { depression } \\
\text { at follow up }\end{array}$ & $\begin{array}{l}\text { Baseline } \\
\text { scores }\end{array}$ & $\begin{array}{l}\text { Follow up } \\
\text { scores }\end{array}$ & $\begin{array}{l}\text { Time of follow } \\
\text { up } \\
\text { (months) }\end{array}$ \\
\hline No $(n=97)$ & $11.1(7.6)$ & $14.0(9.0)$ & $19.1(9.7)$ \\
Minor $(n=18)$ & $12.3(7.6)$ & $19.5(7.4)$ & $18.1(5.6)$ \\
Major $(n=6)$ & $18.0(8.3)$ & $24.8(4.8)$ & $17.3(13.2)$ \\
\hline
\end{tabular}

Data are mean $(S D)$. Group effect $\left(F_{(2,94)}=5.58, p=0.005\right)$, time effect $\left(F_{(1,94)}=16.3, p<0.0001\right)$, group by time interaction $\left(F_{(2,94)}=2.11, N S\right)$. activities, and older age is itself associated with decreased social interaction. On the other hand, our finding that apathy was relatively frequent in the stages of mild $(28 \%)$ and moderate $\mathrm{AD}(39 \%)$, and that $39 \%$ of patients with severe $\mathrm{AD}$ had no apathy suggests that severe cognitive deficits are neither necessary nor sufficient to produce apathy.

Our study also demonstrated a significant association between apathy and depression, an expected finding given phenomenological commonalities between both syndromes. However, depression was neither necessary $(23 \%$ of nondepressed patients had apathy) nor sufficient $(45 \%$ of patients with major depression and $49 \%$ of patients with minor depression had no apathy) to produce apathy. These findings support the suggestion from Levy that apathy should not be construed as a mere symptom of depression in dementia. ${ }^{18}$ Moreover, our study demonstrated that patients who became depressed during the follow up period did not develop more severe apathy at follow up than patients without depression, supporting the nosological separation between apathy and depression in AD.

In a recent study, Boyle and coworkers ${ }^{19}$ found that after accounting for both depression and cognitive deficits, apathy was significantly correlated with more severe functional

Table 3 MMSE and FIM scores at baseline and at follow up for patients with or without apathy at both assessments, and for patients having no apathy at baseline but apathy at follow up

\begin{tabular}{|c|c|c|c|}
\hline & $\begin{array}{l}\text { No apathy } \\
\text { at both } \\
\text { assessments }\end{array}$ & $\begin{array}{l}\text { Apathy } \\
\text { at both } \\
\text { assessments }\end{array}$ & $\begin{array}{l}\text { No apathy } \\
\text { at baseline, } \\
\text { apathy at } \\
\text { follow up }\end{array}$ \\
\hline \multicolumn{4}{|l|}{ MMSE } \\
\hline No. of patients & 138 & 60 & 41 \\
\hline Interval (months) & 18.1 (8.9) & $17.2(10.0)$ & $20.5(8.3)$ \\
\hline Baseline score & $23.6(5.4)$ & $19.8(6.2)$ & $20.5(5.0)$ \\
\hline Follow up score & $23.2(6.3)$ & $17.8(7.2)$ & $16.8(6.8)$ \\
\hline \multicolumn{4}{|l|}{ FIM } \\
\hline No. of patients & 126 & 56 & 37 \\
\hline Interval (months) & $18.0(8.7)$ & $18.2(9.6)$ & 20.1 (10.7) \\
\hline Baseline score & $67.1(6.4)$ & $61.3(6.6)$ & 64.9 (12.2) \\
\hline Follow up score & $65.2(7.1)$ & $56.8(16.8)$ & $56.2(14.0)$ \\
\hline
\end{tabular}

Data are mean (SD). MMSE: group effect $\left(\mathrm{F}_{(2,236)}=8.70, \mathrm{p}=0.0002\right)$, time effect $\left(F_{(1,236)}=33.8, p<0.0001\right)$, group by time interaction $\left(F_{(2,236)}=7.39, p=0.0007\right)$. FIM: group effect $\left(F_{(2,216)}=13.8\right.$, $p<0.0001)$, time effect $\left(F_{(1,216)}=31.0, p<0.0001\right)$, group by time interaction $\left(F_{(2,216)}=5.17, p=0.006\right)$. 
deficits. Our study not only replicated this association, but also demonstrated for the first time that patients who developed apathy during the follow up period had a more rapid cognitive and functional decline than patients without apathy. These findings suggest that apathy is a behavioural marker of a more "malignant" type of $\mathrm{AD}$, with more severe behavioural problems and a faster progression of cognitive, functional, and emotional deficits. Whether the successful treatment of apathy may reduce the progression of these impairments and improve the quality of life for patients and caregivers should be examined in future studies.

\section{ACKNOWLEDGEMENTS}

This study was partially supported with grants from the University of Western Australia, the Australian Rotary Health Research Fund, the Raine Medical Research Foundation, the Fremantle Hospital Research Foundation, and the National Health and Medical Research Council. We are grateful toto Drs E Chemerinski, G Petracca, and L Garau and to A Cao (MA) for data collection.

\section{Authors' affiliations}

S E Starkstein, School of Psychiatry and Clinical Neurosciences, University of Western Australia, and Fremantle Hospital, Western Australia, Australia

R Jorge, R G Robinson, Department of Psychiatry, University of lowa, lowa City, USA

R Mizrahi, PET Center for Addiction and Mental Health, Clarke Division, Toronto, Canada

Competing interests: none

\section{REFERENCES}

1 Marin RS. Apathy: a neuropsychiatric syndrome. J Neuropsychiatry Clin Neurosci 1991;3:243-54.

2 Landes AM, Sperry SD, Strauss ME, Geldmacher DS. Apathy in Alzheimer's disease. J Am Geriatr Soc 2001;49:1700-7.
3 Starkstein SE, Petracca G, Chemerinski E, et al. Syndromic validity of apathy in Alzheimer's disease. Am J Psychiatry 2001;158:872-7.

4 Benoit M, Dygai I, Migneco O, et al. Behavioral and psychological symptoms in Alzheimer's disease. Relation between apathy and regional cerebral perfusion. Dement Geriatr Cogn Disord 1999;10:51 1-17.

5 Benoit M, Clairet S, Koulibaly PM, et al. Brain perfusion correlates of the apathy inventory dimensions of Alzheimer's disease. Int I Geriatr Psychiatry 2004; 19:864-9.

6 Craig AH, Cummings JL, Fairbanks L, et al. Cerebral blood flow correlates of apathy in Alzheimer disease. Arch Neurol 1996;53:1116-20.

7 McKhann G, Drachman D, Folstein M, et al. Clinical diagnosis of Alzheimer's disease: report of the NINCDS-ADRDA Work Group, under the auspices of Department of Health and Human Services Task Force on Alzheimer's Disease. Neurology 1984;34:939-44.

8 Spitzer RL, Williams JB, Gibbon M, et al. The Structured Clinical Interview for DSM-III-R (SCID). I: History, rationale, and description. Arch Gen Psychiatry 1992;49:624-9.

9 American Psychiatric Association. Diagnostic and statistical manual of mental disorders, 4th ed. Washington, DC: American Psychiatric Press, 1994.

10 Chemerinski E, Petracca G, Sabe L, et al. The specificity of depressive symptoms in patients with Alzheimer's disease. Am J Psychiatry 2001;158:68-72

11 Folstein MF, Folstein SE, McHugh PR. "Mini-mental state". A practical method for grading the cognitive state of patients for the clinician. I Psychiatr Res 1975; 12:189-98.

12 Hughes $\mathrm{CP}$, Berg L, Danziger WL, et al. A new clinical scale for the staging of dementia. Br J Psychiatry 1982;140:566-72.

13 Hamilton M. A rating scale for depression. J Neurol Neurosurg Psychiatry 1960;23:56-62.

14 Starkstein SE, Migliorelli R, Manes F, et al. The prevalence and clinical correlates of apathy and irritability in Alzheimer's disease. Eur I Neurol 1995;2:540-6.

15 Granger CV, Hamilton BB, Kayton R. Guide for use of the uniform data set for medical rehabilitation. Buffalo, NY: Uniform Data System for Medical Rehabilitation, 1986.

16 Migliorelli R, Teson A, Sabe L, et al. Anosognosia in Alzheimer's disease: a study of associated factors. J Neuropsychiatry Clin Neurosci 1995;7:338-44.

17 Starkstein SE, Ingram L, Garau LM, et al. On the overlap between apathy and depression in dementia. J Neurol Neurosurg Psychiatry, 2005;76:1070-4.

18 Levy ML, Cummings JL, Fairbanks LA, et al. Apathy is not depression. J Neuropsychiatry Clin Neurosci 1998;10:314-19.

19 Boyle PA, Malloy PF, Salloway S, et al. Executive dysfunction and apathy predict functional impairment in Alzheimer disease. Am J Geriatr Psychiatr 2003;11:214-21 